Article

\title{
Eigen Fuzzy Sets and their Application to Evaluate the Effectiveness of Actions in Decision Problems
}

\author{
Ferdinando Di Martino ${ }^{1,2, *(\mathbb{D})}$ and Salvatore Sessa ${ }^{1,2}$ (D) \\ 1 Dipartimento di Architettura, Università degli Studi di Napoli Federico II, Via Toledo 402, \\ 80134 Napoli, Italy; sessa@unina.it \\ 2 Centro Interdipartimentale di Ricerca “Alberto Calza Bini”,Università degli Studi di Napoli Federico II, \\ Via Toledo 402, 80134 Napoli, Italy \\ * Correspondence: fdimarti@unina.it; Tel.: +39-0812538908; Fax: +39-081238905
}

Received: 21 October 2020; Accepted: 6 November 2020; Published: 9 November 2020

check for updates

\begin{abstract}
We propose a new method based on the greatest (resp., smallest) eigen fuzzy set (GEFS, resp., SEFS) of a fuzzy relation $\mathrm{R}$ with respect to the max-min (resp., min-max) composition in order to implement the actions of a decisor. Using information derived from judgments of the evaluators on how much a characteristic is improved with respect to others, we construct the fuzzy relations, RMAX (resp., RMIN), where any entry RMAX ${ }_{i j}$ (resp., RMIN $_{i j}$ ) expresses how much the efficacy produced on the $i$ th characteristic is equal to or greater (resp., lesser) than that one produced by the $j$ th characteristic. The GEFS of RMAX (resp., SEFS of RMIN) are calculated in order to improve the performances of each characteristic. In the wake of previous applications based on GEFS and SEFS, we propose a method to evaluate the tourism enhancement policies in the historical center of an important Italian city. This method is new and different from those known in the literature so far. It is applied to evaluate benefits brought about by locals in order to enhance tourism in a historical center Comparison tests show that the results obtained are consistent with those expressed by the tourists interviewed
\end{abstract}

Keywords: GEFS; SEFS; fuzzy relations: fuzzy sets; max-min composition; min-max composition

\section{Introduction}

The greatest eigen fuzzy set (for short, GEFS) of a fuzzy relation with respect to the max-min composition and the smallest eigen fuzzy set (SEFS) of it with respect to the min-max decomposition have been studied in [1-4].

GEFS and SEFS have been applied to problems of image information retrieval [5,6], image analysis [7], and image reconstruction [8,9]. In [9-11], a hybrid method is proposed in which GEFS and SEFS are applied to construct a fitness function of a genetic algorithm used for image reconstruction.

In [12-15], GEFS and SEFS are applied to evaluate the effectiveness of pharmaceutical treatments prescribed to patients in the presence of specific symptoms, considering the influence that the symptoms have on each other. In [16], GEFS and SEFS are applied in decision-making problems.

In [14], the authors proposed a method based on GEFS and SEFS to evaluate the effectiveness of Bayer's aspirin in making throat inflammation symptoms disappear in patients after treatment.

Two NxN fuzzy relations $\mathrm{R}_{\mathrm{MAX}}$ and $\mathrm{R}_{\mathrm{MIN}}$ are constructed where the entry $\mathrm{R}_{\mathrm{MAX} i j}$ measures how the action of the drug on the $i$ th symptom is considered equal to or stronger than the $j$ th one, and $\mathrm{R}_{\mathrm{MIN} i j}$ measures how much the action of the drug on the $i$ th symptom is considered equal to or weaker than the $j$ th one. Let $A_{M A X}$ and $B_{M I N}$ be the GEFS of $R_{M A X}$ and the SEFS of $R_{M I N}$, respectively. The authors of $[13,14]$ conclude that Bayer's aspirin removes the $i$ th symptom in a range between $B_{M I N i}$ and $A_{M A X}$. 
We propose to extend this model to analyze a generic problem in which we need to evaluate the effectiveness of an action applied on entities for the purpose of improving their performance.

By this term, we mean an evaluation of the real benefit brought by an action performed on an entity in terms of protection and/or performance improvement. In this context, we generalize the terms entity and action, meaning by entity any object or set of objects described by a set of characteristics and with action any generic action performed on the entity whose possible benefits are to be assessed.

For example, if it is intended to evaluate the effectiveness of a drug on patients who present a specific disease, the entity is constituted by the patients and the action consists of the use of the drug by the patients; the measure of the effectiveness of the action is carried out by analyzing the variation of the patient's characteristics, consisting of the symptoms of the disease.

Another example refers to the evaluation of the performance improvement of the services provided by an infrastructure. In this case, the entity is constituted by the infrastructure and the action is constituted by the works carried out to make the infrastructure more efficient. The characteristics of the entity consist of those attributes that determine its performance.

The aim of this research was to extend the method proposed in [14] in order to apply it in various contexts and to extract an evaluation of both the effectiveness of the action in improving the characteristic of the entity and the uncertainty of this evaluation.

We have tested our method on a problem of tourist enhancement of a historic center. In specific interviews with tourists who had visited the place during the previous year, they were asked to which extent they felt that one of the tourist attractions of the historic center had improved compared to the other ones. In this way, $R_{M A X}$ and $R_{M I N}$ relations were built, and consequently, $A_{M A X}$ and $B_{M I N}$ were determined.

The mean value of the $i$ th component of $\mathrm{A}_{\mathrm{MAX}}$ and $\mathrm{B}_{\mathrm{MIN}}$ provides an estimate of the effectiveness of the action: the difference between the $i$ th components of $A_{\text {MAX }}$ and $B_{\text {MIN }}$ provide the uncertainty of this estimate.

In Section 2, we discuss the concepts of the eigen fuzzy set of a fuzzy relation with respect to the max-min and min-max operators, and we show how GEFS and SEFS can be found as well. In Section 3, we introduce the proposed method based on GEFS and SEFS applied to evaluate the effectiveness of an action on entities. In Section 4, we show the results of our tests. In Section 5, final considerations are given for future studies.

\section{Preliminaries}

The theory of eigen fuzzy sets of fuzzy relations is prevalent in the literature. For example, in [17], eigen fuzzy sets are determined via evolutionary algorithms and neural nets for solving fuzzy relation equations. In [18], subsystems of a fuzzy transition system are characterized in terms of eigen fuzzy sets, in [19], some properties of nilpotent fuzzy matrices are determined in terms of eigen fuzzy sets, and in [20], this concept is used for application to linear differential equations. Fuzzy matrices are useful in various fuzzy systems, with products usually determined by the max-min rule, which is well known in fuzzy set theory. The min-max rule is the duality of the max-min rule, and it is also used in fuzzy systems theory. On the other hand, sufficient conditions for convergence under max-min (and consequently under min-max, for duality) products are well known (e.g., see [21]). In [22], a generalization of the greatest eigen fuzzy sets is proposed.

For making this paper self-contained, we recall well-known results from [1,2]. Let $X=\left\{x_{1}, x_{2}, \ldots\right.$, $\left.x_{n}\right\}$ be a universe of discourse given by a finite set and let $R$ be a fuzzy relation defined on $X \times X, R: X \times$ $X \rightarrow[0,1]$. Furthermore, let $A$ be a fuzzy set of $X$, that is $A: X^{\circledR}[0,1]$, such that

$$
\mathrm{R} \circ \mathrm{A}=\mathrm{A}
$$


where the symbol "o" denotes the well-known max-min composition operator. A is called eigen fuzzy set of $R$ with respect to the max-min composition. In terms of membership functions, Equation (1) is read as

$$
\mathrm{A}(\mathrm{y})=\max \{\min \{\mathrm{A}(\mathrm{x}), \mathrm{R}(\mathrm{x}, \mathrm{y})\}: \mathrm{x} \in \mathrm{X}\} .
$$

We define the fuzzy set $A_{0}$ of $X$ where $A_{0}(y)=a=\min \{\max R(x, y): x \in X\}$ for every $y \in X . A_{0}$ is an eigen fuzzy set as it satisfies Equation (2). In fact, we obtain for every $y \in X$ :

$A_{0}(y)=\max \left\{\min \left\{A_{0}(x), R(x, y)\right\}: x \in X\right\}=\max \{\min \{a, R(x, y)\}: x \in X\}=\min \{\{a, \max R(x, y)\}: x \in X\}=a$.

Now, let $A_{i} i=1,2, \ldots$ be fuzzy sets of $X$ defined recursively by

$$
\mathrm{A}_{1}(\mathrm{y})=\max \{\mathrm{R}(\mathrm{x}, \mathrm{y}): \mathrm{x} \in \mathrm{X}\} \quad \forall \mathrm{y} \in \mathrm{X}, \quad \mathrm{A}_{2}=\mathrm{R} \circ \mathrm{A}_{1}, \ldots, \mathrm{A}_{\mathrm{n}+1}=\mathrm{R} \circ \mathrm{A}_{\mathrm{n}}, \ldots
$$

The following theorem holds:

Theorem 1. ([2]): $A_{i+1} \subseteq A_{i}$ for every $i=1,2, \ldots, n, \ldots$

Proof. We have $A_{2} \subseteq A_{1}$, since $A_{2}(y)=\max \left\{\min \left\{A_{1}(x), R(x, y)\right\}: x \in X\right\} \leq \max \{R(x, y): x \in X\}=A_{1}(y)$ for every $\mathrm{y} \in \mathrm{X}$. Then, we suppose that $\mathrm{A}_{n} \subseteq \mathrm{A}_{n-1}$ and prove that $\mathrm{A}_{n+1} \subseteq \mathrm{A}_{n}$ by induction. Indeed, we have every $\mathrm{y} \in \mathrm{X}$ that $\mathrm{A}_{n+1}(\mathrm{y})=\max \left\{\min \left\{\mathrm{A}_{n}(\mathrm{x}), \mathrm{R}(\mathrm{x}, \mathrm{y})\right\}: \mathrm{x} \in \mathrm{X}\right\} \leq \max \left\{\min \left\{\mathrm{A}_{n-1}(\mathrm{x}), \mathrm{R}(\mathrm{x}, \mathrm{y})\right\}: \mathrm{x} \in \mathrm{X}\right\}$ as $\mathrm{A}_{n} \subseteq \mathrm{A}_{n-1}$.

It is easy to see that $A_{0} \subseteq A_{1}$, since $\left.A_{0}(y)=\max \{\min \{a, R(x, y)\}: x \in X\} \leq \max \{R(x, y)\}: x \in X\right\}=A_{1}(y)$ for every $\mathrm{y} \in \mathrm{X}$. Moreover, being $\mathrm{A}_{0} \subseteq \mathrm{A}_{1}$ and thus $\mathrm{A}_{0}=\mathrm{R} \circ \mathrm{A}_{0} \subseteq \mathrm{R} \circ \mathrm{A}_{1}=\mathrm{A}_{2}$. By Theorem 1 , then we have that

$$
\mathrm{A}_{0} \subseteq \ldots \subseteq \mathrm{A}_{n} \subseteq \mathrm{A}_{n-1} \subseteq \ldots \subseteq \mathrm{A}_{1} .
$$

We search the greatest eigen fuzzy set of $\mathrm{R}$ with respect to the max-min composition. In accordance to the known literature (e.g., $[1,12,18,19])$, there exists the smallest integer $\mathrm{p} \in\{1, \ldots$,cardX $\}$ such that $\mathrm{A}_{p+1}=\mathrm{R} \circ \mathrm{A}_{p}=\mathrm{A}_{p}$; furthermore, $\mathrm{A}_{\mathrm{p}}(\mathrm{x}) \geq \mathrm{A}(\mathrm{x})$ for every $\mathrm{x} \in \mathrm{X}$ and $\mathrm{A} \in \mathrm{F}(\mathrm{X})$ satisfying Equation (1), that is, $A_{p}$ is the greatest eigen fuzzy set of $R$. The following illustrative example make the above concepts clear. $\square$

Example. We consider the following fuzzy relation:

$$
\mathrm{R}=\left(\begin{array}{lllll}
0.3 & 0.7 & 0.6 & 0.5 & 0.8 \\
0.9 & 0.3 & 0.1 & 0.2 & 0.4 \\
0.6 & 0.5 & 0.4 & 1.0 & 0.7 \\
0.2 & 0.8 & 0.2 & 0.1 & 0.6 \\
1.0 & 0.4 & 0.4 & 0.6 & 0.3
\end{array}\right) .
$$

As $\min \left\{\left\{\max _{x \in X} R(x, z)\right\}: z \in X\right\}=\min \{1.0,0.8,0.6,1.0,0.8\}=0.6$, then

$\mathrm{A}_{0}==\min \{\max R(x, z): z \in X\}=\{0.6,0.6,0.6,0.6,0.6\}$.

Furthermore, by recursion, we obtain that

$\mathrm{A}_{1}=\{1.0,0.8,0.6,1.0,0.8\}$,

$\mathrm{A}_{2}=\mathrm{R} \circ \mathrm{A}_{1}=\{0.8,0.8,0.6,0.6,0.8\}$,

$\mathrm{A}_{3}=\mathrm{R} \circ \mathrm{A}_{2}=\mathrm{A}_{2}$.

Then, $p=2$ and $A_{2}$ is the GEFS of $\mathrm{R}$.

Let $B$ be a fuzzy set of $X$. The dual operator of the max-min composition (1) is given by

$$
\mathrm{R} \bullet \mathrm{B}=\mathrm{B}
$$


where " $\bullet$ " denotes the min-max composition and B is said an eigen fuzzy set of $R$ with respect to the min-max composition. In terms of membership functions, Equation (5) is read for every $\mathrm{y} \in \mathrm{X}$ as

$$
\mathrm{B}(\mathrm{y})=\min \{\max \{\mathrm{B}(\mathrm{x}), \mathrm{R}(\mathrm{x}, \mathrm{y})\}: \mathrm{x} \in \mathrm{X}\} .
$$

We define the fuzzy set $B_{0}$ of $X$ where $B_{0}(y)=b=\max \{\min R(x, z): z \in X\}$ for every $y \in X . B_{0}$ is an eigen fuzzy set satisfying Equation (6). In fact, we obtain for every $y \in X$ :

$$
\mathrm{B}_{0}(\mathrm{y})=\min _{\mathrm{x} \in \mathrm{X}}\left\{\max \left\{\mathrm{B}_{0}(\mathrm{x}), \mathrm{R}(\mathrm{x}, \mathrm{y})\right\}\right\}=\min _{\mathrm{x} \in \mathrm{X}}(\max \{\mathrm{b}, \mathrm{R}(\mathrm{x}, \mathrm{y})\})=\max \left\{\mathrm{b}, \min _{\mathrm{x} \in \mathrm{X}} \mathrm{R}(\mathrm{x}, \mathrm{y})\right\}=\mathrm{b}=\mathrm{B}_{0}(\mathrm{y}) .
$$

Let $\mathrm{B}_{\mathrm{i}} i=1,2, \ldots$ be fuzzy sets of $\mathrm{X}$ defined recursively by

$$
\mathrm{B}_{1}(\mathrm{y})=\min _{\mathrm{x} \in \mathrm{X}} \mathrm{R}(\mathrm{x}, \mathrm{y}) \quad \forall \mathrm{y} \in \mathrm{X}, \quad \mathrm{B}_{2}=\mathrm{R} \bullet \mathrm{B}_{1}, \ldots, \mathrm{B}_{\mathrm{n}+1}=\mathrm{R} \bullet \mathrm{B}_{n}, \ldots
$$

For the principle of duality, the following theorem holds:

Theorem 2. ([2]): $B_{i+1} \supseteq B_{i} \forall i=1,2, \ldots, n, \ldots$

Since $B_{0} \supseteq B_{1}$ and $B_{0}$ is an eigen fuzzy set of $R$ with respect to the min-max composition, we deduce that $\mathrm{B}_{0}=\mathrm{R} \circ \mathrm{B}_{0} \supseteq \mathrm{R} \circ \mathrm{B}_{1}=\mathrm{B}_{2}$.

Then, we obtain by Theorem 2:

$$
\mathrm{B}_{0} \supseteq \ldots \supseteq \mathrm{B}_{\mathrm{n}} \supseteq \mathrm{B}_{n-1} \supseteq \ldots \supseteq \mathrm{B}_{1} .
$$

We search the smallest eigen fuzzy set of $\mathrm{R}$ with respect to the min-max composition. By the principle of duality, it is easily seen that there exists the smallest integer $q \in\{1, \ldots$,card $X\}$ such that $\mathrm{B}_{\mathrm{q}+1}=\mathrm{R} \bullet \mathrm{B}_{\mathrm{q}}=\mathrm{B}_{\mathrm{q}}$; furthermore, $\mathrm{B}_{\mathrm{q}}(\mathrm{x}) \leq \mathrm{B}(\mathrm{x})$ for any $\mathrm{x} \in \mathrm{X}$ and fuzzy set $\mathrm{B}$ of $\mathrm{X}$ satisfying Equation (5), that is, $\mathrm{B}_{\mathrm{q}}$ is the smallest eigen fuzzy set (SEFS) of $\mathrm{R}$.

Returning to the above example, by using the sequence defined from (7), we have that $q=1$, since

$\mathrm{B}_{1}=\min _{\mathrm{x} \in \mathrm{X}} \mathrm{R}(\mathrm{x}, \mathrm{z})=(0.2,0.3,0.1,0.1,0.3)$

$\mathrm{B}_{2}=\mathrm{R} \bullet \mathrm{B}_{1}=(0.2,0.3,0.2,0.1,0.3)$

$\mathrm{B}_{3}=\mathrm{R} \bullet \mathrm{B}_{2}=\mathrm{B}_{2}=(0.2,0.3,0.1,0.1,0.3)$.

Then, $q=2$ and $\mathrm{B}_{2}$ is the SEFS of $\mathrm{R}$.

The sequences defined from (3) and (6) are used in our tests, where $\mathrm{N}=$ cardX $=256$.

\section{The Proposed Method}

We propose to apply the GEFS and SEFS to study the effect produced by an action performed on entities to safeguard them or improve their performances (for example, a restoration or maintenance intervention on a damaged or degraded building, or a medical treatment prescribed to a patient to eradicate a disease). We intend to generalize the method proposed in [14] to evaluate the effectiveness of a drug in making a symptom of a disease disappear in patients.

Let $X=\left\{x_{1}, x_{2}, \ldots, x_{n}\right\}$ be an universe of discourse given by a set of positive or negative characteristics of the entity that highlights its good condition (or its degradation). We consider a fuzzy relation $R_{M A X}$ whose entry $R_{M A X}$ is a value in $[0,1]$, representing how much the action performed on the entity has enhanced the positive characteristic (or has attenuated the negative characteristic) $\mathrm{x}_{i}$ more or in the same way as $\mathrm{x}_{j}$. The values of $\mathrm{R}_{\mathrm{MAX}_{i j}}$ are obtained by investing $\mathrm{N}$ evaluators who, due to the action performed, consider that the characteristic $x_{i}$ is enhanced (or attenuated) in a manner equal to or greater than $x_{j}$. If $n_{i j}$ is the number of evaluators considering $x_{i}$ enhanced (or attenuated) in a manner equal to or greater than $x_{j}$, we compute

$$
\mathrm{R}_{\mathrm{MAX} i j}=\frac{\mathrm{n}_{i j}}{\mathrm{~N}}
$$


The element $\mathrm{R}_{\mathrm{MAX} i i}$ represents the percentage of evaluators considering $\mathrm{x}_{i}$ enhanced (or attenuated) and not modified after the intervention performed. The GEFS of $R_{M A X}$ is given by the fuzzy set $A_{M A X}$ satisfying the equation:

$$
\mathrm{R}_{\text {MAX }} \circ \mathrm{A}_{\text {MAX }}=\mathrm{A}_{\text {MAX }} .
$$

We can interpret $\mathrm{A}_{\mathrm{MAX} i}$ as the maximum effect produced by the intervention enhancing (or mitigating) the $i$ th characteristics. Furthermore, we consider a fuzzy relation $\mathrm{R}_{\mathrm{MIN}}$ whose entry $\mathrm{R}_{\mathrm{MIN} i j}$ is a value in $[0,1]$ representing how much the intervention produced on the entities has attenuated the negative characteristic $S_{i}$ less than or at least in the same way as $\mathrm{x}_{j}$. If $\mathrm{m}_{i j}$ is the number of evaluators considering $x_{i}$ enhanced (or attenuated) to a lesser or identical extent with respect to $x_{j}$, we compute as

$$
\mathrm{R}_{\mathrm{MIN} i j}=\frac{\mathrm{m}_{i j}}{\mathrm{~N}}
$$

The SEFS of $\mathrm{R}_{\mathrm{MIN}}$ is given by the fuzzy set $\mathrm{B}_{\mathrm{MIN}}$ satisfying the equation:

$$
\mathrm{R}_{\mathrm{MIN}} \circ \mathrm{B}_{\mathrm{MIN}}=\mathrm{B}_{\mathrm{MIN}} \text {. }
$$

We can interpret $\mathrm{B}_{\mathrm{MINi}}$ as the minimum effect produced by the action performed enhancing (or mitigating) the $i$ th characteristics. Then, the interval $\left[\mathrm{B}_{\mathrm{MIN} i}, \mathrm{~A}_{\mathrm{MAX}}\right]$ can represent the range of effectiveness of the action in enhancing (or mitigating) the $i$ th characteristics. We consider the mean value given by

$$
\mathrm{E}_{i}=\frac{\left(\mathrm{A}_{\mathrm{MAX} i}+\mathrm{B}_{\mathrm{MIN} i}\right)}{2}
$$

as the mean effectiveness of the action in enhancing (mitigating) the $i$ th characteristics. The value

$$
\mathrm{U}_{i}=\frac{\left(\mathrm{A}_{\mathrm{MAX} i}-\mathrm{B}_{\mathrm{MIN} i}\right)}{2}
$$

is considered as the mean uncertainty in the evaluation of the effectiveness of the action in enhancing (or mitigating) the $i$ th characteristics. The effectiveness of the action in enhancing (or mitigating) the $i$ th characteristics will be evaluated as $\mathrm{E}_{i} \pm \mathrm{U}_{i}$.

The block diagram of the proposed algorithm is shown in Figure 1.

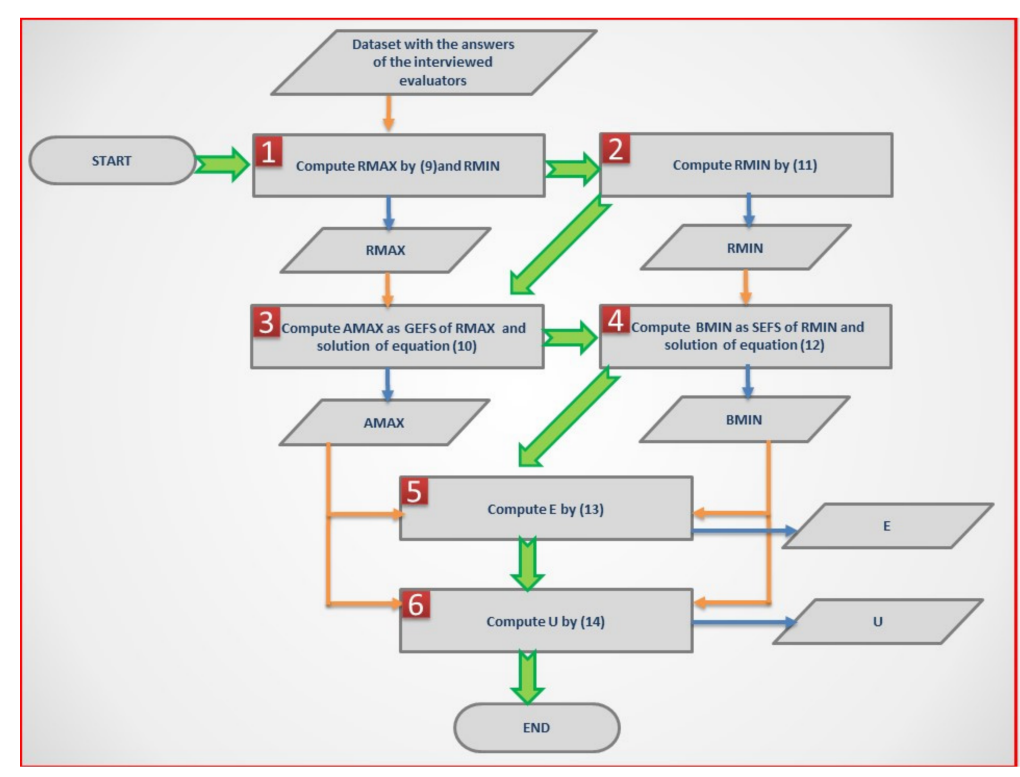

Figure 1. Block diagram schematizing the proposed algorithm. 
The processes are represented with rectangles, and the input and output data to the processes are represented with parallelograms. Processes are numbered according to the sequential order in which they are executed in the algorithm. The green arrows link each process to the next process. The yellow arrows connect input data to the process, and the blue arrows show the output data obtained after the process execution is complete.

The pseudocode of the proposed Algorithm 1 is shown below.

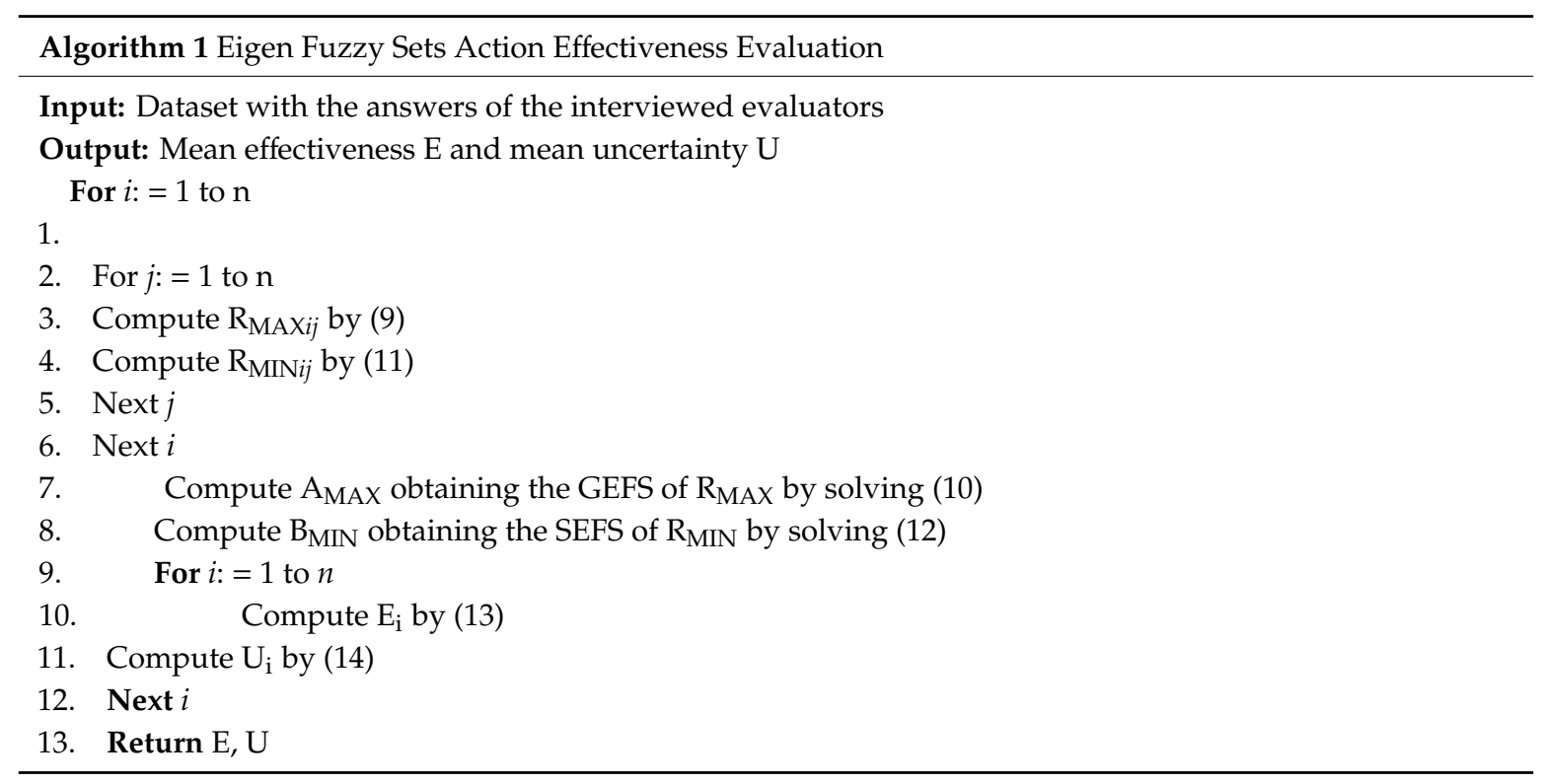

\section{An Illustrative Example}

We applied our method to analyze any benefits brought about by local policies over a year in order to enhance tourism in a historical center. The calculation processes are developed in Microsoft Excel, and the results of this test are included in our shared repository https://drive.google.com/file/d/ 17t3QWbu06xX3B63A10o6imMsCtSj2Iz6/view?usp=sharing.

In this example, the universe of discourse is given by six positive and negative characteristics of a historic urban center that represents a pole of cultural tourist attraction. The six characteristics (the first three negative and the last three positive) are the following:

$\mathrm{x}_{1}$ : "poor variety and quality of museum services as information and booking points"

$\mathrm{x}_{2}$ : "poor reachability of museums by public transport"

$\mathrm{x}_{3}$ : "high state of decay of some monuments and churches"

$\mathrm{x}_{4}$ : "discrete presence of equipped hotel facilities in the historic city center"

$\mathrm{x}_{5}$ : "good presence of restaurants and entertainment venues in the historical city center"

$\mathrm{x}_{6}$ : "discrete presence in the historic center of furnished housing units for tourist use".

We carried out our tests, made recently, considering the historical center of the municipality of Naples, in Italy. The evaluators were about 150 tourists who visited the historical center of the city of Naples in 2019 and who were asked to evaluate how much these characteristics had improved between them after a year because of policies to enhance the cultural tourism heritage pursued by the local administration. We construct the fuzzy relations $R_{\text {MAX }}$ and $R_{\text {MIN }}$ by (9) and (11), respectively.

The component $\mathrm{R}_{\mathrm{MAX} i j}$ represents how much the $i$ th characteristic is improved better or to the same extent as the $j$ th one. For example, the entry $\mathrm{R}_{\mathrm{MAX} 1,2}$ contains as information to what extent the interviewed tourists assess that the action implemented has reduced the poor variety and quality of museum services as information and booking points in an equal or more effective way than the poor reachability of museums by public transport. The $\mathrm{R}_{\mathrm{MAX} 14}$ entry contains as information to what extent the interviewed tourists assess that the action implemented has reduced the poor variety and 
quality of museum services as information and booking points in an equal or greater manner than the improvement of the discrete presence of equipped hotel facilities in the historical city center.

We apply the proposed algorithm to evaluate the effectiveness of the implementation of the policies applied to enhance the cultural tourism heritage and to improve the six characteristics.

The two matrices $\mathrm{R}_{\mathrm{MAX}}, \mathrm{R}_{\mathrm{MIN}}$, GEFS, and SEFS are shown in Tables 1-3, respectively.

Table 1. R $\mathrm{MAX}$.

\begin{tabular}{ccccccc}
\hline $\mathbf{R}_{\mathbf{M A X}}$ & $\mathbf{x}_{\mathbf{1}}$ & $\mathbf{x}_{\mathbf{2}}$ & $\mathbf{x}_{\mathbf{3}}$ & $\mathbf{x}_{\mathbf{4}}$ & $\mathbf{x}_{\mathbf{5}}$ & $\mathbf{x}_{\mathbf{6}}$ \\
\hline $\mathbf{x}_{\mathbf{1}}$ & 0.5 & 0.4 & 0.6 & 0.6 & 0.5 & 0.5 \\
$\mathbf{x}_{\mathbf{2}}$ & 0.7 & 0.8 & 0.7 & 0.8 & 0.6 & 0.5 \\
$\mathbf{x}_{\mathbf{3}}$ & 0.6 & 0.4 & 0.6 & 0.6 & 0.5 & 0.4 \\
$\mathbf{x}_{\mathbf{4}}$ & 0.5 & 0.2 & 0.4 & 0.3 & 0.4 & 0.2 \\
$\mathbf{x}_{\mathbf{5}}$ & 0.5 & 0.4 & 0.6 & 0.7 & 0.5 & 0.5 \\
$\mathbf{x}_{\mathbf{6}}$ & 0.6 & 0.5 & 0.6 & 0.8 & 0.6 & 0.7 \\
\hline
\end{tabular}

Table 2. $\mathrm{R}_{\mathrm{MIN}}$.

\begin{tabular}{ccccccc}
\hline $\mathbf{R}_{\text {MIN }}$ & $\mathbf{x}_{\mathbf{1}}$ & $\mathbf{x}_{\mathbf{2}}$ & $\mathbf{x}_{\mathbf{3}}$ & $\mathbf{x}_{\mathbf{4}}$ & $\mathbf{x}_{\mathbf{5}}$ & $\mathbf{x}_{\mathbf{6}}$ \\
\hline $\mathbf{x}_{\mathbf{1}}$ & 0.5 & 0.7 & 0.6 & 0.5 & 0.5 & 0.6 \\
$\mathbf{x}_{\mathbf{2}}$ & 0.4 & 0.8 & 0.4 & 0.2 & 0.4 & 0.5 \\
$\mathbf{x}_{\mathbf{3}}$ & 0.6 & 0.7 & 0.6 & 0.4 & 0.6 & 0.6 \\
$\mathbf{x}_{\mathbf{4}}$ & 0.6 & 0.8 & 0.6 & 0.3 & 0.7 & 0.8 \\
$\mathbf{x}_{\mathbf{5}}$ & 0.5 & 0.6 & 0.5 & 0.4 & 0.5 & 0.6 \\
$\mathbf{x}_{\mathbf{6}}$ & 0.5 & 0.5 & 0.4 & 0.2 & 0.5 & 0.7 \\
\hline
\end{tabular}

Table 3. Greatest eigen fuzzy set (GEFS) of $\mathrm{R}_{\mathrm{MAX}}$ and SEFS of $\mathrm{R}_{\mathrm{MIN}}$.

\begin{tabular}{ccccccc}
\hline & $\mathbf{x}_{\mathbf{1}}$ & $\mathbf{x}_{\mathbf{2}}$ & $\mathbf{x}_{\mathbf{3}}$ & $\mathbf{x}_{\mathbf{4}}$ & $\mathbf{x}_{\mathbf{5}}$ & $\mathbf{x}_{\mathbf{6}}$ \\
\hline $\mathbf{A}_{\text {MAX }}$ & 0.7 & 0.8 & 0.6 & 0.6 & 0.6 & 0.7 \\
$\mathbf{B}_{\text {MIN }}$ & 0.5 & 0.5 & 0.5 & 0.3 & 0.5 & 0.5 \\
$\mathbf{E}$ & 0.60 & 0.65 & 0.55 & 0.45 & 0.55 & 0.60 \\
$\mathbf{U}$ & 0.10 & 0.15 & 0.05 & 0.15 & 0.05 & 0.10 \\
\hline
\end{tabular}

The characteristic $\mathrm{x}_{2}$ "poor reachability of museums by public transport" is that one on which the policies of the cultural tourism heritage are most affected $\left(\mathrm{E}_{2}=0.65\right)$. On the contrary, the characteristic $\mathrm{x}_{4}$ "discrete presence of equipped hotel facilities in the historic city center" is that one on which the implementation of these policies has had the least impact, even if worsening the characteristic $\mathrm{x}_{4}\left(\mathrm{E}_{4}=0.45\right)$. The characteristics $\mathrm{x}_{3}$ and $\mathrm{x}_{5}$ are those for which the uncertainty in evaluating the effectiveness produced by the implementation of these policies is the smallest one $\left(\mathrm{U}_{3}=\mathrm{U}_{5}=0.05\right)$.

To perform a comparison analysis of our method, we compare the results in Table 3 with the percentage of preferences assigned to each characteristic by the tourists. Each tourist interviewed was also asked to indicate which of the six characteristics had improved more significantly compared with last year.

Table 1 shows for each characteristic the number of preferences for which the characteristic improved more significantly and its percentage value calculated with respect to the total number of interviews.

The characteristic that improved most significantly for the largest number of respondents (approximately 23\%) was characteristic $x_{2}$. About 20\% of the respondents believed that the characteristics that improved most significantly were characteristics $x_{1}$ and $x_{6} ; 14 \%$ of them thought that the characteristic that improved most significantly was characteristic $x_{5}$ and $13 \%$ of them thought that the characteristic that improved most significantly was characteristic $x_{3}$. Finally, only about $10 \%$ of respondents believed that the characteristic that improved most significantly was characteristic $\mathrm{x}_{4}$. 
The results in Table 4 are consistent with those obtained by applying the proposed method, as the higher the value of the mean effectiveness of the action in enhancing a characteristic of the entity, the higher the percentage of preferences assigned by the tourists interviewed to that characteristic.

Table 4. Preferences expressed by tourists about the characteristics that improved most significantly.

\begin{tabular}{cccccccc}
\hline & $\mathbf{x}_{\mathbf{1}}$ & $\mathbf{x}_{\mathbf{2}}$ & $\mathbf{x}_{\mathbf{3}}$ & $\mathbf{x}_{\mathbf{4}}$ & $\mathbf{x}_{\mathbf{5}}$ & $\mathbf{x}_{\mathbf{6}}$ & Tot \\
\hline Number of preferences & 30 & 35 & 20 & 15 & 21 & 31 & 152 \\
Percentage of preferences & $19.74 \%$ & $23.03 \%$ & $13.16 \%$ & $9.87 \%$ & $13.82 \%$ & $20.39 \%$ & $100.00 \%$ \\
\hline
\end{tabular}

\section{Conclusions}

We propose a method based on GEFS and SEFS to evaluate the effect produced by an action performed on entities to safeguard them or improve their performances. These performances are measured considering their characteristics: a set of evaluators express judgments on how much a characteristic is improved in comparison to others. This information allows creating two fuzzy relations, $\mathrm{R}_{\mathrm{MAX}}$ and $\mathrm{R}_{\mathrm{MIN}}$, where $\mathrm{R}_{\mathrm{MAX} i j}$ expresses the percentage evaluating how the efficacy produced on the $i$ th characteristic is equal to or greater than that produced by the $j$ th characteristic. Conversely, $\mathrm{R}_{\mathrm{MIN} i j}$ expresses the percentage evaluating how the efficacy produced on the $i$ th characteristic is equal to or less than that produced by the $j$ th characteristic. We compute the GEFS of $R_{\text {MAX }}$ and the SEFS of $R_{\text {MIN }}$ to assess how effective the action produced was regarding increasing the performances of each characteristic.

In the future, we intend to experiment with our method the extraction of information relating to the judgments given by evaluators expressed essentially in social groups in order to increase the number of judgments and therefore to obtain less uncertain assessments of the effectiveness of the action taken.

Author Contributions: Conceptualization, F.D.M. and S.S.; methodology, F.D.M. and S.S.; software, F.D.M. and S.S.; validation, F.D.M. and S.S.; formal analysis, F.D.M. and S.S.; investigation, F.D.M. and S.S.; resources, F.D.M. and S.S.; data curation, F.D.M. and S.S.; writing - original draft preparation, F.D.M. and S.S.; writing-review and editing, F.D.M. and S.S.; visualization, F.D.M. and S.S.; supervision, F.D.M. and S.S. All authors have read and agreed to the published version of the manuscript.

Funding: This research received no external funding.

Conflicts of Interest: The authors declare no conflict of interest.

\section{References}

1. Sanchez, E. Resolution of eigen fuzzy sets equation. Fuzzy Sets Syst. 1978, 1, 69-74. [CrossRef]

2. Sanchez, E. Eigen fuzzy sets and fuzzy relations. J. Math. Anal. Appl. 1981, 81, 399-421. [CrossRef]

3. Wagenknecht, M.; Hartmann, K. On the construction of fuzzy eigen solutions in given regions. Fuzzy Sets Syst. 1986, 20, 55-65. [CrossRef]

4. Bourke, M.M.; Grant Fisher, D. Convergence, eigen fuzzy sets and stability analysis of relation matrices. Fuzzy Sets Syst. 1996, 8, 227-234. [CrossRef]

5. Di Martino, F.; Nobuhara, H.; Sessa, S. Eigen fuzzy sets and image information retrieval. In Proceedings of the 2004 IEEE International Conference on Fuzzy Systems, Budapest, Hungary, 25-29 July 2004; pp. 1285-1390. [CrossRef]

6. Di Martino, F.; Nobuhara, H.; Sessa, S. Eigen fuzzy sets and image information retrieval. In Handbook of Granular Computing; Pedrycz, W., Skowron, A., Kreinovich, V., Eds.; Wiley: New York, NY, USA, 2008; pp. 863-872, ISBN 9780470035542.

7. Nobuhara, H.; Hirota, K. A solution for eigen fuzzy sets of adjoint max-min decomposition and its application to image analysis. In Proceedings of the IEEE International Symposium on Intelligent Signal Processing, Budapest, Hungary, 4-6 September 2003; pp. 27-30.

8. Nobuhara, H.; Bede, B.; Hirota, K. On various eigen fuzzy sets and their application to image reconstruction. Inf. Sci. 2006, 176, 2988-3010. [CrossRef] 
9. Di Martino, F.; Sessa, S. A Genetic Algorithm Based on Eigen Fuzzy Sets for Image Reconstruction. In Applications of Fuzzy Sets Theory; Lecture Notes in Computer Science; Masulli, F., Mitra, S., Pasi, G., Eds.; Springer: Berlin/Heidelberg, Germany, 2007; Volume 4578, pp. 342-348. [CrossRef]

10. Nobuhara, H.; Iyoda, E.M.; Bede, B.; Hirota, K. A solution for generalized eigen fuzzy sets equations by genetic algorithms and its application to image analysis. In Proceedings of the 2nd International IEEE Conference on Intelligent Systems, Varna, Bulgaria, 22-24 June 2004; Volume 1, pp. 208-212. [CrossRef]

11. Di Martino, F.; Sessa, S. Image matching by using fuzzy transforms. Adv. Fuzzy Syst. 2013, $2013,760704$. [CrossRef]

12. Gestenkorn, T.; Rakus-Andersson, E. An application of fuzzy set theory to differentiating the effectiveness of drugs in treatment of inflammation of genital organs. Fuzzy Sets Syst. 1994, 68, 327-333. [CrossRef]

13. Rakus-Andersson, E. An application of fuzzy numbers in eigen fuzzy set problem to differentiating the effectiveness of drugs. In Proceedings of the International Conference on Fuzzy Information Processing: Theories and Applications, Bejing, China, 1-4 March 2003; Tsinghua University Press: Bejing, China; Springer: Berlin, Germany, 2003; pp. 85-90.

14. Rakus-Andersson, E. The greatest and the least eigen fuzzy sets in evaluation of the drug effectiveness levels. In Artificial Intelligence and Soft Computing-ICAISC 2006; Lecture Notes in Computer Science; Rutkowski, L., Tadeusiewicz, R., Zadeh, L.A., Żurada, J.M., Eds.; Springer: Berlin/Heidelberg, Germany, 2006; Volume 402. [CrossRef]

15. Rakus-Andersson, E. Fuzzy and rough techniques in medical diagnosis and medication. In Studies in Fuzziness and Soft Computing; Springer: Berlin/Heidelberg, Germany, 2007; Volume 212, ISBN 103540497072.

16. Guleria, A.; Bajaj, R.K. Eigen spherical fuzzy sets and its application in decision making problem, Scientia Iranica. Int. J. Sci. Technol. 2019, 2019, 29. [CrossRef]

17. Buckley, J.; Feuring, T.; Hayashi, Y. Solving fuzzy equations using evolutionary algorithms and neural nets. Soft Comput. 2002, 6, 116-123. [CrossRef]

18. Ignjatović, J.; Ćirić, M.; Simović, V. Fuzzy relation equations and subsystems of fuzzy transition systems. Knowl. Based Syst. 2013, 38, 48-61. [CrossRef]

19. Lur, Y.-Y.; Pang, C.-T.; Guu, S.-M. On nilpotent fuzzy matrices. Fuzzy Sets Syst. 2004, 145, 287-299. [CrossRef]

20. Mizukoshi, M.T.; Lodwick, W.A. The interval eigenvalue problem using constraint interval analysis with an application to linear differential equations. Fuzzy Sets Syst. 2020, in press. [CrossRef]

21. Thomason, M.G. Convergence of powers of a fuzzy matrix. J. Math. Anal. Appl. 1977, 57, 476-480. [CrossRef]

22. Fernández, M.J.; Suárez, F.; Gil, P. T-eigen fuzzy sets. Inf. Sci. 1993, 75, 63-80. [CrossRef]

Publisher's Note: MDPI stays neutral with regard to jurisdictional claims in published maps and institutional affiliations.

(C) 2020 by the authors. Licensee MDPI, Basel, Switzerland. This article is an open access article distributed under the terms and conditions of the Creative Commons Attribution (CC BY) license (http://creativecommons.org/licenses/by/4.0/). 